\title{
Quantitative EEG and functional outcome following acute ischemic stroke
}

\author{
Carla Bentes ${ }^{\mathrm{a}, \mathrm{b}, 1, *}$, Ana Rita Peralta ${ }^{\mathrm{a}, \mathrm{b}, 1}$, Pedro Viana ${ }^{\mathrm{a}, \mathrm{b}}$, Hugo Martins ${ }^{\mathrm{c}}$, Carlos Morgado ${ }^{\mathrm{b}, \mathrm{d}}$, \\ Carlos Casimiro $^{\mathrm{d}}$, Ana Catarina Franco ${ }^{\mathrm{a}}$, Ana Catarina Fonseca ${ }^{\mathrm{a}, \mathrm{b}}$, Ruth Geraldes ${ }^{\mathrm{a}, \mathrm{b}}$, Patrícia Canhão ${ }^{\mathrm{a}, \mathrm{b}}$, \\ Teresa Pinho e Melo ${ }^{\mathrm{a}, \mathrm{b}}$, Teresa Paiva ${ }^{\mathrm{e}}$, José M. Ferro ${ }^{\mathrm{a}, \mathrm{b}}$ \\ ${ }^{a}$ EEG/Sleep Laboratory and Stroke Unit, Department of Neurosciences and Mental Health (Neurology), Hospital de Santa Maria - CHLN, Avenida Professor Egas Moniz, Lisboa \\ 1649-035, Portugal \\ ${ }^{\mathrm{b}}$ Faculty of Medicine, Universidade de Lisboa, Avenida Professor Egas Moniz, Lisboa 1649-035, Portugal \\ ${ }^{\mathrm{c}}$ Department of Medicine, Hospital de São José - CHLC, R. José António Serrano, Lisboa 1150-199, Portugal \\ d Department of Neuroradiology, Hospital de Santa Maria - CHLN, Avenida Professor Egas Moniz, Lisboa 1649-035, Portugal \\ ${ }^{\mathrm{e}}$ Eletroencefalography and Clinic Neurophysiology Centre (CENC), R. Conde Antas 5, Lisboa 1070-079, Portugal
}

\section{A R T I C L E I N F O}

\section{Article history:}

Accepted 8 May 2018

Available online 18 June 2018

\section{Keywords:}

Ischemic stroke

Functional outcome

Quantitative EEG

Alpha relative power

Delta-theta to alpha-beta ratio

\section{H I G H L I G H T S}

- EEG powers in the alpha, beta and delta bands are independent predictors of post-stroke outcome.

- Delta-theta to alpha-beta ratio and alpha relative power are good qEEG stroke outcome predictors.

- Quantitative EEG indices improve the discriminative capacity of outcome models of acute stroke.

\begin{abstract}
A B S T R A C T
Objective: To identify the most accurate quantitative electroencephalographic (qEEG) predictor(s) of unfavorable post-ischemic stroke outcome, and its discriminative capacity compared to already known demographic, clinical and imaging prognostic markers.

Methods: Prospective cohort of 151 consecutive anterior circulation ischemic stroke patients followed for 12 months. EEG was recorded within $72 \mathrm{~h}$ and at discharge or 7 days post-stroke. QEEG (global band power, symmetry, affected/unaffected hemisphere and time changes) indices were calculated from mean Fast Fourier Transform and analyzed as predictors of unfavorable outcome ( $\mathrm{mRS} \geq 3$ ), at discharge and 12 months poststroke, before and after adjustment for age, admission NIHSS and ASPECTS.

Results: Higher delta, lower alpha and beta relative powers (RP) predicted outcome. Indices with higher discriminative capacity were delta-theta to alpha-beta ratio (DTABR) and alpha RP. Outcome models including either of these and other clinical/imaging stroke outcome predictors were superior to models without qEEG data. In models with qEEG indices, infarct size was not a significant outcome predictor. Conclusions: DTAABR and alpha RP are the best qEEG indices and superior to ASPECTS in post-stroke outcome prediction. They improve the discriminative capacity of already known clinical and imaging stroke outcome predictors, both at discharge and 12 months after stroke.

Significance: qEEG indices are independent predictors of stroke outcome.
\end{abstract}

(c) 2018 International Federation of Clinical Neurophysiology. Published by Elsevier B.V. All rights reserved.
Abbreviations: ADCI, Acute Delta Change Index; ASCI, Acute Symmetry Change Index; ASPECTS, Alberta Stroke Program Early CT score; BSI, Brain Symmetry Index; DTABR, delta-theta to alphabeta ratio; Ln, natural logarithm; mRS, modified Rankin Scale; NIHSS, National Institutes of Health Stroke Scale; qEEG, quantitative EEG.

* Corresponding author at: EEG/Sleep Laboratory and Stroke Unit, Department of Neurosciences and Mental Health (Neurology), Hospital de Santa Maria - CHLN, Avenida Professor Egas Moniz, Lisboa 1649-035, Portugal.

E-mail addresses: ccbentes@gmail.com, carlabentes@campus.ul.pt (C. Bentes).

1 These authors contributed equally to the work.

\section{Introduction}

Stroke is a leading cause of disability and mortality worldwide, and despite advances in disease prevention, acute treatment and rehabilitation, global stroke burden is expected to rise in the future (Feigin et al., 2017). Early post-stroke prognostication is essential both in the short-term (f. ex. in guiding treatment strategies) and 
in the long-term (to aid in rehabilitation management, in order to improve recovery and minimize disability). Predictors of stroke disability and associate death consistently include age and clinical / imaging related stroke severity (Adams et al., 1999; Barber et al., 2000; Frankel et al., 2000; Hankey, 2003; Hankey et al., 2007; Konig et al., 2008; Knoflach et al., 2012; Vogt et al., 2012). However, despite the existence of demographic, clinical and imaging factors that can be associated with functional outcome, early prediction of short and long-term post-stroke outcome is challenging since there is large interindividual variability (Stinear, 2010). Therefore, there is still need to identify reliable, inexpensive biomarkers that can add prognostic information in these patients. Due to accumulating evidence regarding neuro-vascular uncoupling in acute ischemic stroke, neurophysiological biomarkers seem increasingly relevant for predicting outcome (Rossini et al., 2004).

EEG is a non-invasive, inexpensive diagnostic method, with high temporal resolution, contributing to a rapid evaluation of instantaneous brain function. However, its visual interpretation requires technical experience, and may be subject to interrater variability. Hence, quantitative EEG (qEEG) techniques have emerged and have been proven informative in stroke prognostication (Finnigan and van Putten, 2013). These techniques have the advantage of providing objective, rater-independent information, which can be used in a variety of settings, including intensive care units. Previous studies have also shown they can be equal to, or even be more informative, than visual EEG interpretation for detecting cerebral pathology (Sainio et al., 1983; Nuwer et al., 1987; Cillessen et al., 1994; Murri et al., 1998).

In general, EEG parameters such as total power, relative delta and alpha power, ratios between slower and faster frequencies (such as the delta/alpha ratio [DAR] and the [delta + theta/alpha + beta] ratio [DTABR]), and brain symmetry indices (such as the Brain Symmetry Index [BSI] and pair-derived BSI) have been strongly associated with stroke outcome, for up to 12 months (Finnigan and van Putten, 2013). These measures have also been shown, in some studies, to be more reliable in prognostication than standard clinical evaluation (Cuspineda et al., 2003; Finnigan et al., 2007; Diedler et al., 2010; Sheorajpanday et al., 2010, 2011b) or imaging biomarkers (Finnigan et al., 2004; Sheorajpanday et al., 2010, 2011b).

However, direct comparison of these measures and indices for predicting stroke outcome has yielded conflicting results (Finnigan and van Putten, 2013). Moreover, few previous studies attempted to control for independent known outcome factors, such as age at stroke onset, clinical severity at admission or infarct size.

Therefore, the principal objectives of this study were: (1) to identify the most accurate qEEG measure(s) associated with outcome at discharge and 12 months after stroke, (2) to compare the discriminative capacity of outcome models based exclusively in already known demographic, clinical and imaging prognostic markers and including one qEEG variable, and (3) to compare qEEG and visual EEG analysis in stroke outcome prediction, in a large, well defined cohort of acute anterior circulation ischemic stroke patients.

\section{Methods}

\subsection{Study design}

Study design has been previously described (Bentes et al., 2017b). We performed a prospective longitudinal study of consecutive anterior circulation ischemic stroke patients admitted to the Stroke Unit of the Neurology Department of a University Hospital, over a period of 24 months (from October 2011 to October 2013) and followed for 12 months. The Ethics Committee "Comissão de Ética para a Saúde" of our hospital approved the study. All subjects or their next of kin gave written informed consent for participation. All included patients had to be previously independent (modified Rankin Scale $[\mathrm{mRS}] \leq 1)$, have a National Institutes of Health Stroke Scale score (NIHSS) $\geq 4$ (Goldstein et al., 1989) upon admission to the emergency department, have an acute ischemic brain lesion (CT scan or MRI) in the internal carotid artery territory and no previous history of epileptic seizures nor traumatic head injury requiring hospital admission.

\subsection{Clinical assessment}

All patients received standardized clinical and diagnostic assessment, during admission and after discharge. An investigator blinded to the neurophysiological evaluation conducted a phone interview at six months and a clinical appointment 12 months after stroke to access the occurrence of epileptic seizures and functional outcome. Clinical stroke severity was assessed by NIHSS at admission. The functional outcome at discharge and at 12 months was assessed by the mRS scale (Banks and Marotta, 2007).

\subsection{Neuroimaging interpretation}

A senior neuroradiologist, (C.M. or C.C.) blinded for clinical and electroencephalographic findings analyzed the neuroimaging studies. Doubts were decided by consensus. In patients with middle cerebral artery stroke, infarct size was quantified by the Alberta Stroke Program Early Computed Tomography Score (ASPECTS) (Barber et al., 2000) in an acute brain CT (computed tomography) scan performed in the first $24 \mathrm{~h}$ after stroke.

\subsection{Neurophysiological evaluation}

Patients underwent a neurophysiological evaluation protocol that included a 64-channel video-EEG with a maximum duration of $60 \mathrm{~min}$ in the first $72 \mathrm{~h}$ after stroke (first EEG). A similar EEG was also collected at discharge or on the 7th day post-stroke (second EEG). The neurophysiological protocol was previously described (Bentes et al., 2017a). The record included an eyesclosed, wake resting condition and eyes-open, hyperventilation and photic stimulation activation maneuvers. Raw EEG review was performed by a certified clinical neurophysiologist (CB) using international criteria and terminology (Noachtar et al., 1999; Beniczky et al., 2013; Hirsch et al., 2013), blinded for clinical and imaging findings. All doubts were decided by consensus with another clinical neurophysiologist (ARP).

\subsubsection{EEG acquisition}

The EEG was recorded in a Nihon-Kohden device with a sample frequency of $1000 \mathrm{~Hz}$. Consecutive samples of EEG, acquired in similar technical conditions (eyes closed, resting condition outside hyperventilation, photic stimulation or sleep) and with the best possible technical quality, were selected forming an EEG segment of $1-10 \mathrm{~min}$.

\subsubsection{EEG processing}

EEG segments (high cutoff filter $70 \mathrm{~Hz}$; low cutoff filter $0.5 \mathrm{~Hz}$; notch filter $50 \mathrm{~Hz}$, average montage) were exported for FTT analysis in BESA software (BESA Research 6.0, June 2013, BESA GmbH, Graefelting, Germany). In BESA, visual and automatic rejection of artifacts was done. When present, blinking artifacts were also removed by principal component analysis. The EEG was then segmented into 2.05s mini-epochs and FFT analysis was performed for each of these segments. Mean Fast Fourier Transform (FFT) of all the $2.05 \mathrm{~s}$ mini-epochs of the selected EEG segment was computed 
in the following frequency bands: Delta $-1-4 \mathrm{~Hz}$; Theta $-4-8 \mathrm{~Hz}$; Alfa $-8-12 \mathrm{~Hz}$; Beta - 12-30 Hz. Relative (RP) and absolute power (AP) in these frequency bands was obtained.

\subsubsection{Computed indices ( $q E E G$ predictors)}

Several qEEG indices were calculated from both hemispheres, the affected and unaffected hemisphere, from the first and second EEG recordings, and in the frequency bands described in Section 2.4.2. Details for qEEG index calculation are presented in Supplementary Appendix A.

Computed indices were: global relative power indices including delta, theta, alpha and beta relative power, as well as ratios between slow and fast frequencies (slow (delta-theta) and fast (alfa-beta) frequencies ratio (DTABR), delta and alpha ratio (DAR)). Furthermore, symmetry indices included the brain symmetry index (BSI) and the ratio between affected and unaffected hemisphere RP. We also calculated affected and unaffected hemisphere indices. Lastly, we computed time changes indices, reflecting the dynamic changes between the first $(0-72 \mathrm{~h})$ and second EEG (discharge or 7th day post-stroke): Acute Symmetry Change Index (ASCI), Acute Delta, Alpha, Theta and Beta Change Indices, and Acute DTABR Change Index. For simplicity purposes, only results concerning the global relative power indices are reported in the main document. Results from other indices can be found in Supplementary Appendix B. EEG indices were, whenever necessary, transformed to their natural logarithm or square root in order to have normal distribution and homogeneity of variances, as required for logistic regression models.

\subsection{Outcomes}

The outcomes in this study were an unfavorable functional outcome ( $\mathrm{mRS} \geq 3$ ) at discharge and 12 months after stroke.

\subsection{Statistical analysis}

EEG spectral indices were evaluated using descriptive statistics (mean and standard deviation) in patients with unfavorable and favorable outcome at discharge (first EEG indices) and 12 months (first, second and dynamic EEG evolution indices) post-stroke. Bivariate analyses were performed between groups using $t$-test after confirming their normal distribution (Shapiro Wilk and Kolmogorov Smirnov tests) or Mann-Whitney test in non-normal variables. Prognostic models were constructed using logistic regression. Homogeneity of variances was confirmed with the Levene test, and model calibration was analyzed by Hosmer-Lemeshow. QEEG variables with a significant association in the bivariate analysis were adjusted for known functional outcome predictors of stroke (Adams et al., 1999; Barber et al., 2000; Knoflach et al., 2012; Vogt et al., 2012), namely age, clinical stroke severity (admission NIHSS) and imaging infarct size (ASPECTS). All logistic models were constructed with only one qEEG variable plus these previously known outcome predictors, in order to avoid the multicolinearity between qEEG variables. Logistic models were performed with the neurophysiological variables in their natural logarithm ( Ln) or square root transformation to comply with the model requisites.

Additionally, to assess the overall internal validation of each model, a 10-fold cross-validation technique was implemented. After dividing the dataset into 10 random folds, we used N-1 (9) folds to calculate the model coefficients, which were then applied to the remaining fold to yield fitted values for these observations. The process was repeated 10 times using different folds of the data. Finally, we used the fitted values to obtain a cross-validated area under the ROC curve (cvAUC) and corresponding 95\% confidence intervals.

Using DeLong tests, the outcome prediction model including the qEEG index with highest cvAUCs was compared with the model including exclusively known stroke outcome predictors, as well as with models using known predictors and visual EEG analysis variables, namely background activity asymmetry. EEG background asymmetry was chosen in accordance to a previous report where it was shown that this was the variable more strongly associated with anterior circulation ischaemic stroke outcome (Bentes et al., 2017c). Cut-off values were calculated for various sensitivities and specificities. The significance level was $\alpha \leq 0.05$. Statistical analysis was performed using SPSS program version 24 for Mac, and STATA 14.2 for Mac (Statacorp $\left.{ }^{\circledR}\right)$.

\section{Results}

\subsection{Study population}

One-hundred-and-fifty-one patients (112 men and 39 women) were included, with a mean age of 67.4 (S.D. 11.9) years. During the study period, 23 patients died (seven during admission before day 7). One patient (0.66\%) was lost for clinical follow-up at 12 months. All patients had at least one acute CT scan and D1 EEG. In 8 patients, D7 EEG was not performed. One patient had bilateral middle cerebral artery stroke and was not included. Study flowchart and further details of the sample studied have been previously described (Bentes et al., 2017c).

\subsection{Functional outcome at discharge and at 12 months}

\subsubsection{Bivariate analyses}

All patients were included in the analysis. The average duration of the EEG segments used for FFT calculation, after artifact removal was $248 \pm 222 \mathrm{~s}$ (median $213 \mathrm{~s}$ ). Tables 1 and 2 show the main qEEG indices calculated for patients who were alive and independent at discharge and at 12 months, respectively, as compared to patients who died or were dependent at these time points. Most qEEG indices show significant differences between these two groups. Overall, dependence or death at discharge is associated with EEGs with higher slow frequency (delta) and lower high frequency (alpha and beta) powers, both in overall EEG power and in each hemisphere separately (affected and unaffected). Further results from the bivariate analysis are found in Supplementary Appendix B.

\subsubsection{Multivariate analyses}

On multivariate analysis, after controlling for admission NIHSS, age and ASPECTS, most of the neurophysiological variables remained independent predictors of outcome (Supplementary Appendix B).

After 10-fold cross-validation, the variables rendering models with highest cvAUC were DTABR, and alpha RP. Therefore, models including DTABR or alpha RP were chosen for ROC comparison with both the known functional outcome predictors model and the model with visual EEG analysis of background asymmetry (Fig. 1). While DTABR is associated with the highest cvAUC both at discharge and 12 months, alpha RP was chosen because it is easy to calculate and is less prone to be interfered by artifacts than qEEG indices including lower frequencies.

Table 3 displays the comparison between stroke outcome prediction models characteristics at discharge and 12 months poststroke. For discharge outcome, compared with the known functional outcome predictors model (cvAUC 0.752, 95\% CI 0.671-0.834), both models including DTABR (cvAUC 0.827, 95\% CI 0.758-0.895) or alpha RP (cvAUC 0.814, 95\% CI 0.742-0.885) preform significantly better (DeLong tests: $\mathrm{p}=0.009$ and $\mathrm{p}=$ 0.023 , respectively). The discriminative capacity of models including DTABR or alpha RP was similar (DeLong tests $\mathrm{p}=0.3525$ ). 
Table 1

Quantitative EEG indices and outcome at discharge.

\begin{tabular}{|c|c|c|c|c|c|}
\hline qEEG index & $\begin{array}{l}\mathrm{mRS}<3 \\
(\mathrm{n}=52)\end{array}$ & $\begin{array}{l}m R S \geq 3 \\
(n=99)\end{array}$ & $\begin{array}{l}\text { Bivariate analysis } \\
\mathrm{p}\end{array}$ & $\begin{array}{l}\text { Multivariate analysis OR }(95 \% \mathrm{CI}) \\
\mathrm{p}\end{array}$ & Cross-validated AUC (95\% CI) \\
\hline \multicolumn{6}{|c|}{ 1st EEG $(0-72 \mathrm{~h})$} \\
\hline Delta RP & $\begin{array}{l}0.37 \pm 0.17 \\
(0.37)\end{array}$ & $\begin{array}{l}0.54 \pm 0.17 \\
(0.54)\end{array}$ & $<0.001^{*}$ & $\begin{array}{l}125.0(9.2-1692.4) \\
<0.001^{\mathrm{a}}\end{array}$ & $\begin{array}{l}0.812 \\
(0.740-0.884)\end{array}$ \\
\hline Theta RP & $\begin{array}{l}0.20 \pm 0.08 \\
(0.21)\end{array}$ & $\begin{array}{l}0.22 \pm 0.09 \\
(0.20)\end{array}$ & n.s. ${ }^{+}$ & - & - \\
\hline Alpha RP & $\begin{array}{l}0.23 \pm 0.12 \\
(0.22)\end{array}$ & $\begin{array}{l}0.13 \pm 0.08 \\
(0.11)\end{array}$ & $<0.001^{+}$ & $\begin{array}{l}0.221(0.099-0.492) \\
<0.001^{\mathrm{b}}\end{array}$ & $\begin{array}{l}0.814 \\
(0.742-0.885)\end{array}$ \\
\hline Beta RP & $\begin{array}{l}0.20 \pm 0.13 \\
(0.18)\end{array}$ & $\begin{array}{l}0.12 \pm 0.08 \\
(0.09)\end{array}$ & $<0.001^{+}$ & $\begin{array}{l}0.28(0.140-0.574) \\
<0.001^{\text {b }}\end{array}$ & $\begin{array}{l}0.803 \\
(0.729-0.877)\end{array}$ \\
\hline DTABR & $\begin{array}{l}1.87 \pm 1.45 \\
(1.51)\end{array}$ & $\begin{array}{l}4.61 \pm 3.29 \\
(4.01)\end{array}$ & $<0.001^{+}$ & $\begin{array}{l}1.702(1.297-2.231) \\
\mathrm{p}<0.001^{\mathrm{a}}\end{array}$ & $\begin{array}{l}0.827 \\
(0.758-0.895)\end{array}$ \\
\hline
\end{tabular}

Results in the 2nd and 3rd column are shown as mean \pm standard deviation (median) of the natural logarithm of the EEG index. Multivariate analyses included the variables age, NIHSS at admission and ASPECTS scores plus the EEG index. CI 95\% - 95\% confidence interval; OR - odds ratio; RP - relative power; DTABR - delta-theta to alpha-beta ratio.

*test.

+ Mann-Whitney $U$ test.

a Logistic regression using the untransformed variable.

b Logistic regression using the variable transformed into the natural logarithm.

Table 2

Quantitative EEG indices and outcome at 12 months.

\begin{tabular}{|c|c|c|c|c|c|}
\hline qEEG index & $\begin{array}{l}\mathrm{mRS}<3 \\
(\mathrm{n}=73)\end{array}$ & $\begin{array}{l}\mathrm{mRS} \geq 3 \\
(\mathrm{n}=77)\end{array}$ & $\begin{array}{l}\text { Bivariate analysis } \\
\mathrm{p}\end{array}$ & $\begin{array}{l}\text { Multivariate OR }(95 \% \mathrm{CI}) \\
\mathrm{p}\end{array}$ & Cross-validated AUC (95\% CI) \\
\hline \multicolumn{6}{|c|}{ 1st EEG $(0-72 \mathrm{~h})$} \\
\hline Delta RP & $\begin{array}{l}0.41 \pm 0.17 \\
(0.40)\end{array}$ & $\begin{array}{l}0.56 \pm 0.17 \\
(0.58)\end{array}$ & $<0.001 *$ & $\begin{array}{l}129.8(8.8-1904.5) \\
<0.001^{\mathrm{a}}\end{array}$ & $0.836(0.771-0.900)$ \\
\hline Theta RP & $\begin{array}{l}0.20 \pm 0.09 \\
(0.20)\end{array}$ & $\begin{array}{l}0.22 \pm 0.09 \\
(0.22)\end{array}$ & n.s. ${ }^{+}$ & - & - \\
\hline Alpha RP & $\begin{array}{l}0.21 \pm 0.11 \\
(0.17)\end{array}$ & $\begin{array}{l}0.12 \pm 0.08 \\
(0.11)\end{array}$ & $<0.001^{+}$ & $\begin{array}{l}0.16(0.064-0.380) \\
<0.001^{\text {b }}\end{array}$ & $0.852(0.790-0.913)$ \\
\hline Beta RP & $\begin{array}{l}0.19 \pm 0.12 \\
(0.16)\end{array}$ & $\begin{array}{l}0.11 \pm 0.08 \\
(0.08)\end{array}$ & $<0.001^{+}$ & $\begin{array}{l}0.28(0.137-0.572) \\
<0.001^{\text {b }}\end{array}$ & $\begin{array}{l}0.829 \\
(0.763-0.895)\end{array}$ \\
\hline DTABR & $\begin{array}{l}2.17 \pm 1.56 \\
(1.68)\end{array}$ & $\begin{array}{l}5.12 \pm 3.46 \\
(4.15)\end{array}$ & $<0.001^{+}$ & $\begin{array}{l}1.668(1.297-2.143) \\
p<0.001^{a}\end{array}$ & $\begin{array}{l}0.859 \\
(0.800-0.919)\end{array}$ \\
\hline \multicolumn{6}{|c|}{ 2nd EEG (day 7 or discharge) } \\
\hline Delta RP & $\begin{array}{l}0.37 \pm 0.16 \\
(0.33)\end{array}$ & $\begin{array}{l}0.57 \pm 0.19 \\
(0.57)\end{array}$ & $<0.001^{+}$ & $\begin{array}{l}165.4(13.43-2036.1) \\
<0.001^{\mathrm{a}}\end{array}$ & $\begin{array}{l}0.833 \\
(0.768-0.899)\end{array}$ \\
\hline Theta RP & $\begin{array}{l}0.19 \pm 0.10 \\
(0.15)\end{array}$ & $\begin{array}{l}0.20 \pm 0.09 \\
(0.18)\end{array}$ & n.s. ${ }^{+}$ & - & - \\
\hline Alpha RP & $\begin{array}{l}0.24 \pm 0.13 \\
(0.22)\end{array}$ & $\begin{array}{l}0.13 \pm 0.10 \\
(0.10)\end{array}$ & $<0.001^{+}$ & $\begin{array}{l}0.001(0.000-0.027) \\
<0.001^{\mathrm{c}}\end{array}$ & $\begin{array}{l}0.827 \\
(0.760-0.894)\end{array}$ \\
\hline Beta RP & $\begin{array}{l}0.21 \pm 0.13 \\
(0.18)\end{array}$ & $\begin{array}{l}0.10 \pm 0.09 \\
(0.08)\end{array}$ & $<0.001^{+}$ & $\begin{array}{l}0.319(0.17-0.60) \\
<0.001^{\text {b }}\end{array}$ & $\begin{array}{l}0.819 \\
(0.750-0.888)\end{array}$ \\
\hline DTABR & $\begin{array}{l}1.88 \pm 1.89 \\
(1.25)\end{array}$ & $\begin{array}{l}10.64 \pm 35.91 \\
(4.15)\end{array}$ & $<0.001^{+}$ & $\begin{array}{l}3.17(1.86-5.42) \\
p<0.001^{a}\end{array}$ & $\begin{array}{l}0.843 \\
(0.779-0.907)\end{array}$ \\
\hline
\end{tabular}

Results in the 2nd and 3rd column are shown as mean \pm standard deviation (median) of the natural logarithm of the EEG index. Multivariate analyses included the variables age, NIHSS at admission and ASPECTS scores plus the EEG index. OR - odds ratio; RP - relative power; DTABR - delta-theta to alphabeta ratio.

${ }^{*} t$-test.

+ Mann-Whitney $U$ test.

a Logistic regression using the untransformed variable.

b Logistic regression using the variable transformed into the natural logarithm.

c Logistic regression using the variable transformed into the square root.

Analogously, for 12-month outcome, compared with the model with known functional outcome predictors (cvAUC 0.794, 95\% CI 0.722-0.865), both models including DTABR (cvAUC 0.859, 95\% CI 0.800-0.919) and alpha RP (cvAUC 0.852, 95\% CI 0.790-0.913) had significantly higher discriminative capacity (DeLong tests: $p$ $=0.009$ and $\mathrm{p}=0.015$, respectively). As for discharge, the predictive power of models including DTABR or alpha RP was similar (DeLong tests $\mathrm{p}=0.5482$ ).

Moreover, for both discharge and 12-month unfavorable outcome, NIHSS remains as the only independent predictor together with any of the two qEEG indices.

Finally, visual analysis of EEG background asymmetry was also an independent prognostic marker of poor functional outcome at discharge (cvAUC $0.831,95 \% \mathrm{CI} 0.762-0.900$ ) and 12 months (cvAUC $0.890,95 \%$ CI $0.837-0.943$ ) and performed significantly better than the known functional outcome predictors model alone (DeLong test: 0.010 for discharge and 0.001 for 12 months). The discriminative capacity of the model incorporating visual EEG analysis was not significantly different compared with models with either qEEG index (DTABR - DeLong test: 0.767 for discharge and 0.185 for 12 months; alpha RP - DeLong test: 0.190 for discharge and 0.100 for 12 months).

3.2.2.1. Cutoff values for alpha relative power in the first EEG. Table 4 shows the sensitivity and specificity values for alpha RP obtained from the first EEG, for predicting unfavorable outcome. 

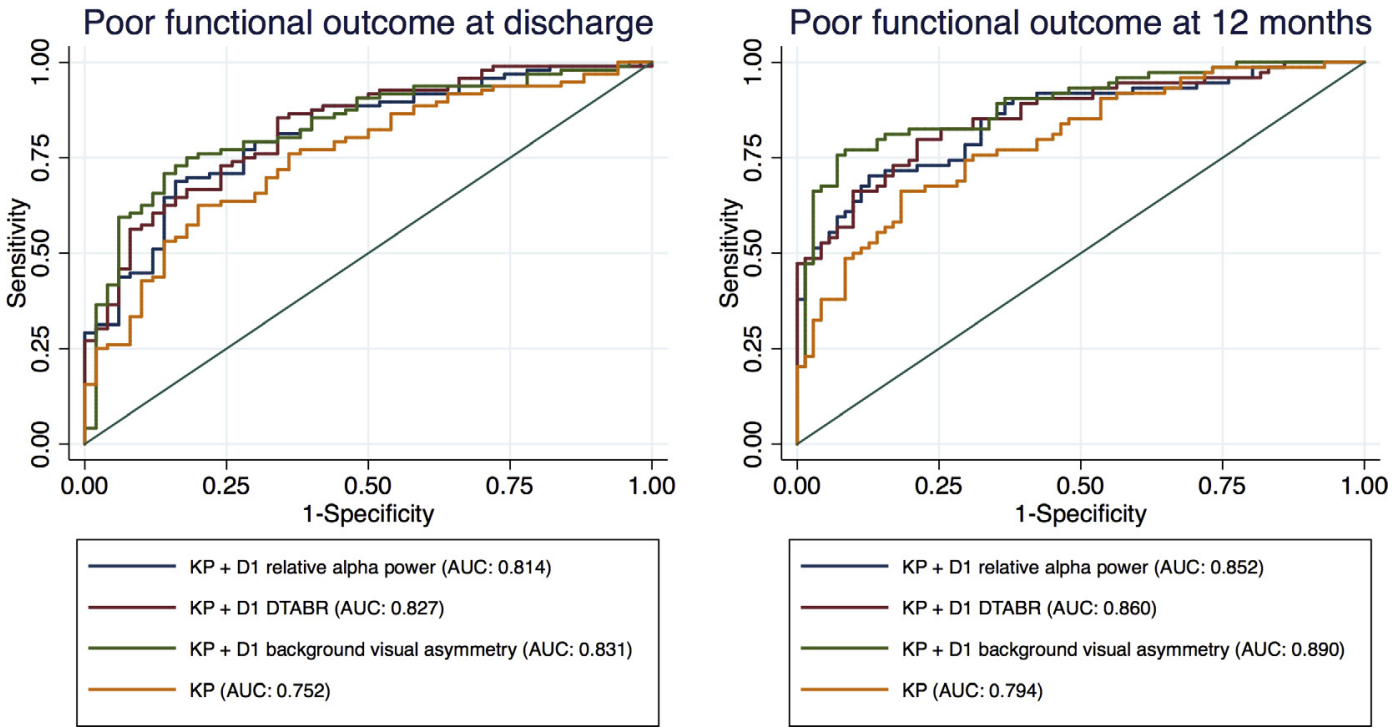

Fig. 1. Receiver Operating Characteristic (ROC) curves for multivariate models including known post-stroke outcome predictors (KP - age, admission NIHSS and ASPECTS), with or without one additional qEEG index (DTABR - delta-theta to alfa-beta ratio or alpha RP - relative power) obtained from the quantitative analysis of the first EEG or visual EEG analysis (background asymmetry) of the same record, in relation to poor functional outcome at discharge (A) and 12 months (B).

Table 3

Comparison between stroke outcome ( $\mathrm{mRS} \geq 3$ ) prediction models characteristics at discharge $(\mathrm{A})$ and 12 months (B).

\begin{tabular}{|c|c|c|c|c|c|c|c|c|c|}
\hline Model & Omnibus Test & $\begin{array}{l}\text { Nagelkerkes } \\
\mathrm{R}^{2}\end{array}$ & $\begin{array}{l}\text { Hosmer \& } \\
\text { Lemeshow test }\end{array}$ & $\begin{array}{l}\text { PAC } \\
(\%)\end{array}$ & $\begin{array}{l}\text { SEN } \\
(\%)\end{array}$ & $\begin{array}{l}\text { SPE } \\
(\%)\end{array}$ & $\begin{array}{l}\text { PPV } \\
(\%)\end{array}$ & $\begin{array}{l}\text { NPV } \\
(\%)\end{array}$ & $\begin{array}{l}\text { Cross-validated AUC } \\
(95 \% \mathrm{CI})\end{array}$ \\
\hline \multicolumn{10}{|c|}{ A. Unfavorable outcome at discharge } \\
\hline $\mathrm{KP}^{\mathrm{a}}$ & $\begin{array}{l}\chi^{2}(3)=34.94 ; p< \\
0.001\end{array}$ & 0.294 & $\begin{array}{l}\chi^{2}(8)=4.90 ; p= \\
0.768\end{array}$ & 73.3 & 85.4 & 50.0 & 76.6 & 64.1 & $0.752(0.671-0.834)$ \\
\hline Alpha $\mathrm{RP}^{\mathrm{b}}$ & $\begin{array}{l}\chi^{2}(1)=28.5 ; P< \\
0.001\end{array}$ & 0.238 & $\begin{array}{l}\chi^{2}(8)=10.1 ; p= \\
0.259\end{array}$ & 72.8 & 86.9 & 46.2 & 75.4 & 64.9 & $0.756(0.674-0.838)$ \\
\hline DTABR $^{\mathrm{b}}$ & $\begin{array}{l}\chi^{2}(1)=37.3 ; \mathrm{P}< \\
0.001\end{array}$ & 0.302 & $\begin{array}{l}\chi^{2}(8)=4.74 ; p= \\
0.785\end{array}$ & 71.5 & 84.8 & 46.2 & 75.0 & 61.5 & $0.785(0.710-0.860)$ \\
\hline $\mathrm{KP}^{\mathrm{a}}+$ alpha $\mathrm{RP}^{\mathrm{b}}$ & $\begin{array}{l}\chi^{2}(4)=50.79 ; p< \\
0.001\end{array}$ & 0.406 & $\begin{array}{l}\chi^{2}(8)=5.07 ; p= \\
0.751\end{array}$ & 76.7 & 85.4 & 60.0 & 80.4 & 68.2 & $0.814(0.742-0.885)$ \\
\hline $\mathrm{KP}^{\mathrm{a}}+\mathrm{DTABR}^{\mathrm{b}}$ & $\begin{array}{l}\chi^{2}(4)=3.73 ; p< \\
0.001\end{array}$ & 0.426 & $\begin{array}{l}\chi^{2}(8)=4.44 ; p= \\
0.816\end{array}$ & 78.1 & 87.5 & 60.0 & 80.7 & 71.4 & $0.827(0.758-0.895)$ \\
\hline $\begin{array}{c}\mathrm{KP}^{\mathrm{a}}+\text { visually analyzed EEG } \\
\text { background asymmetry }\end{array}$ & $\begin{array}{l}\chi^{2}(4)=59.25 ; p< \\
0.001\end{array}$ & 0.461 & $\begin{array}{l}\chi^{2}(8)=3.67 ; \mathrm{p}= \\
0.885\end{array}$ & 76.7 & 81.3 & 68.0 & 82.9 & 65.4 & $0.831(0.762-0.900)$ \\
\hline $\begin{array}{l}\mathrm{KP}^{\mathrm{a}}+\text { visually analyzed EEG } \\
\text { background slowing }{ }^{\mathrm{b}}\end{array}$ & $\begin{array}{l}\chi^{2}(4)=46.61 ; p< \\
0.001\end{array}$ & 0.378 & $\begin{array}{l}\chi^{2}(8)=5.01 ; p= \\
0.756\end{array}$ & 74.7 & 82.3 & 60 & 79.8 & 63.8 & $0.787(0.713-0.861)$ \\
\hline \multicolumn{10}{|c|}{ B. Unfavorable outcome at 12 months } \\
\hline $\mathrm{KP}^{\mathrm{a}}$ & $\begin{array}{l}\chi^{2}(3)=52.15 ; p< \\
0.001\end{array}$ & 0.403 & $\begin{array}{l}\chi^{2}(8)=5.20 ; \mathrm{p}= \\
0.736\end{array}$ & 71.0 & 70.3 & 71.8 & 72.2 & 69.8 & $0.794(0.722-0.865)$ \\
\hline Alpha $\mathrm{RP}^{\mathrm{b}}$ & $\begin{array}{l}\chi^{2}(1)=36.42 ; p< \\
0.001\end{array}$ & 0.287 & $\begin{array}{l}\chi^{2}(8)=15.6 ; p= \\
0.048\end{array}$ & 68.0 & 70.1 & 65.8 & 68.4 & 67.6 & $0.768(0.692-0.844)$ \\
\hline DTABR $^{\mathrm{b}}$ & $\begin{array}{l}\chi^{2}(1)=40.52 ; p< \\
0.001\end{array}$ & 0.316 & $\begin{array}{l}\chi^{2}(8)=9.98 ; p= \\
0.266\end{array}$ & 70.7 & 76.6 & 64.4 & 69.4 & 72.3 & $0.774(0.697-0.850)$ \\
\hline $\mathrm{KP}^{\mathrm{a}}+$ alpha $\mathrm{RP}^{\mathrm{b}}$ & $\begin{array}{l}\chi^{2}(4)=73.48 p< \\
0.001\end{array}$ & 0.530 & $\begin{array}{l}\chi^{2}(8)=6.61 ; p= \\
0.579\end{array}$ & 77.2 & 75.7 & 78.9 & 78.9 & 75.6 & $0.852(0.790-0.913)$ \\
\hline $\mathrm{KP}^{\mathrm{a}}+\mathrm{DTABR}^{\mathrm{b}}$ & $\begin{array}{l}\chi^{2}(4)=73.15 ; p< \\
0.001\end{array}$ & 0.528 & $\begin{array}{l}\chi^{2}(8)=8.78 ; p= \\
0.361\end{array}$ & 77,2 & 79,7 & 74,6 & 76.6 & 77.9 & $0.859(0.800-0.919)$ \\
\hline $\begin{array}{c}\mathrm{KP}^{\mathrm{a}}+\text { visually analyzed EEG } \\
\text { background asymmetry }\end{array}$ & $\begin{array}{l}\chi^{2}(4)=93.52 ; p< \\
0.001\end{array}$ & 0.634 & $\begin{array}{l}\chi^{2}(8)=4.38 ; p= \\
0.82\end{array}$ & 84.8 & 81.1 & 88.7 & 88,2 & 81,8 & $0.890(0.837-0.943)$ \\
\hline $\begin{array}{l}\mathrm{KP}^{\mathrm{a}}+\text { visually analyzed EEG } \\
\text { background slowing }\end{array}$ & $\begin{array}{l}\chi^{2}(4)=83.169 ; p \\
<0.001\end{array}$ & 0.582 & $\begin{array}{l}\chi^{2}(8)=5.96 ; p= \\
0.652\end{array}$ & 82.8 & 78.4 & 87.3 & 84.1 & 79.5 & $0.866(0.808-0.924)$ \\
\hline
\end{tabular}

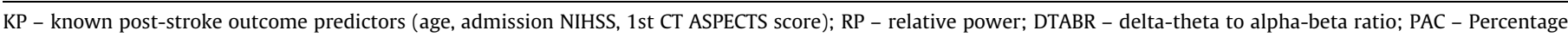

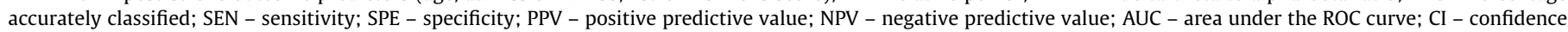
interval.

a Age and ASPECTS are non-significant variables in the model.

b $1^{\text {st }}$ EEG $(0-72 \mathrm{~h})$.

This neurophysiological variable, in isolation, predicts unfavorable outcome with an area under the ROC curve of $0.750(95 \%$ CI $0.669-0.832)$ at discharge and 0.769 (95\%CI $0.695-0.844)$ at 12 months. For both discharge and 12-month outcomes, an alpha $\mathrm{RP}$ lower than $10 \%$ on an EEG performed in the first $72 \mathrm{~h}$ post-stroke shows high specificity to predict unfavorable outcome (87-89\%), despite low sensitivity (37-46\%). Alpha RP below $20 \%$ have higher sensitivity to detect patients with unfavorable outcome (86 and 90\%, respectively) albeit low specificity. 
Table 4

Sensitivity and specificity of different Ln D1 alpha RP values for predicting unfavorable outcome.

\begin{tabular}{|c|c|c|}
\hline 1st EEG $(0-72 \mathrm{~h})$ & Sensitivity & Specificity \\
\hline \multicolumn{3}{|c|}{ Death or functional dependency at discharge ( $m R S \geq 3$ ) } \\
\hline $\begin{array}{l}\text { Ln alpha } R P \leq-2.3 \\
\text { (alpha } R P \leq 10 \% \text { ) }\end{array}$ & $37-46 \%$ & $87-89 \%$ \\
\hline $\begin{array}{l}\text { Ln alpha } R P \leq-1.9 \\
\quad(\text { alpha } R P \leq 15 \%)\end{array}$ & $66-70 \%$ & $67-71 \%$ \\
\hline $\begin{array}{r}\text { Ln alpha } R P \leq-1.6 \\
\text { (alpha } R P \leq 20 \% \text { ) }\end{array}$ & $86 \%$ & $52-54 \%$ \\
\hline \multicolumn{3}{|c|}{ Death or functional dependency at 12-month post-stroke ( $m R S \geq 3$ ) } \\
\hline $\begin{array}{l}\text { Ln alpha } R P \leq-2.3 \\
\text { (alpha } R P \leq 10 \% \text { ) }\end{array}$ & $46-53 \%$ & $86-89 \%$ \\
\hline $\begin{array}{l}\text { Ln alpha } R P \leq-1.9 \\
\quad(\text { alpha } R P \leq 15 \%)\end{array}$ & $71-77 \%$ & $53-66 \%$ \\
\hline $\begin{array}{l}\text { Ln alpha } R P \leq-1.6 \\
\text { (alpha } R P \leq 20 \% \text { ) }\end{array}$ & $90 \%$ & $44-45 \%$ \\
\hline
\end{tabular}

Ln - natural logarithm; RP - relative power.

\section{Discussion}

To the best of our knowledge, this is the largest study evaluating quantitative EEG parameters for prediction of post-stroke functional outcome. In a consecutively selected, well defined, acute anterior circulation ischemic stroke cohort, the predictive accuracy of qEEG measures was examined while controlling for clinical and imaging variables, which are available and easily determined in clinical practice in a stroke unit.

In this study, comparing absolute and relative frequency band power indices, symmetry measures and dynamic time changes, we have shown that most qEEG indices previously reported in the literature are independent prognostic markers for poor functional outcome. Additionally, DTABR and alpha RP are some of the most accurate neurophysiological markers for outcome prediction, both at discharge and 12 months after stroke. Lower alpha RP, higher DTABR and higher NIHSS scores were sufficient to predict poor functional outcome, rendering age and ASPECTs scores non-significant in our models. Furthermore, these qEEG indices seem to provide additional prognostic information to already known clinical and imaging-related predictors, and with similar performance to previously reported visual EEG analysis of background asymmetry. Finally, we report that alpha RP below $10 \%$ is highly specific for a poor functional outcome at both timelines.

Negative correlation between alpha activity and stroke outcome is in accordance with several previous studies (Sainio et al., 1983; Szelies et al., 2002; Cuspineda et al., 2007; Finnigan et al., 2007; Diedler et al., 2010; Schleiger et al., 2014). Alpha frequencies are thought to derive from cortical layers IV and V, whereas slower delta or theta frequencies are generated by the thalamus and cortical layers II-VI (Schuijt et al., 2012). Therefore, it is not surprising that alpha activity disturbances reflect direct cortical injury (Kaplan and Rossetti, 2011). Furthermore, the change in faster frequencies, such as alpha, is thought to precede the increase in slower frequencies, as shown in patients undergoing carotid endarterectomy with continuous EEG and cerebral blood flow measurements (Sharbrough et al., 1973). In 47 patients with unilateral cerebral infarction, relative alpha frequency positively correlated with regional cerebral blood flow and oxygen metabolism, as measured by positron emission tomography (Nagata et al., 1989). The same variable has been positively correlated with cognitive outcome (in a functional assessment scale), as well as with improvement in post-stroke aphasia (Szelies et al., 2002; Schleiger et al., 2014). This assessment might be even extended to critical care ventilated patients, where a decrease in faster frequency activity has been associated with drop in cerebral perfusion pressure (Diedler et al., 2009). In patients presenting with subarachnoid hemorrhage, relative alpha power was able to predict the development of delayed cerebral ischemia (Rathakrishnan et al., 2011). Moreover, alpha activity may rapidly increase after successful reperfusion due to rt-PA administration in acute stroke (Finnigan et al., 2006). In a previous study, we have shown that, in visual EEG analysis, the variables more strongly associated with outcome were background activity slowing and background activity asymmetry (Bentes et al., 2017c). On visual analysis, background slowing is usually related to a decrease in alpha frequency or absent alpha activity. Therefore, the qEEG findings are in accordance with the visual analysis.

Other neurophysiological variables (DTABR, DAR, delta RP), also strongly and independently associated with outcome, incorporate lower frequencies, such as delta power. Delta oscillations usually emerge and have higher voltage in the core lesion of ischemic stroke patients (Murri et al., 1998). They may be more predominant on the affected hemisphere, but their presence in the unaffected side, as measured by EEG and magnetoencephalography, has been described as an important prognostic factor (Finnigan et al., 2007; Tecchio et al., 2007; Assenza et al., 2013). In our sample, the DTABR was the qEEG index that was associated with higher discriminative power in AUC analysis to detect short and longterm poor prognosis after stroke. DTABR correlates negatively with cerebral perfusion accessed by Position Emission Tomography in stroke patients (Nagata et al., 1989) and as been shown to be very sensitive and specific for discriminating between cerebral ischemia and controls (Finnigan et al., 2015) and to be an independent prognostic factor for short-term disability after lacunar stroke (Sheorajpanday et al., 2011a). Sub-acute DTABR also predicted 6 months-disability in an unselected population of stroke patients (Sheorajpanday et al., 2011b). Our data reinforces the importance of this qEEG parameter as a strong predictor for short and long term functional stroke outcome, when obtained as early as the first $72 \mathrm{~h}$ after stroke.

To the best of our knowledge, no previous study directly compared the accuracy of alpha RP and DTABR as functional stroke outcome predictors. Our data suggests that they are not significantly different. In our study, we focused on reporting the predictive value of alpha RP for several reasons. Firstly, our data has shown that models with DTABR and alpha RP have similar discriminative capacities. DTABR, besides requiring a more specific computation, incorporates the delta frequency band that is more frequently interfered by artifacts such as blinking, slow shifts or sudation. In the clinical setting, where continuous EEG signal might not be submitted to the strict scrutiny for artifacts, as in this research, its value may not be comparable. Overall, alpha RP seems a preferable neurophysiological marker as it analyses the brain oscillatory activity with higher signal to noise ratio on scalp EEG. Furthermore, some EEG patterns, such as Rapid Attenuation Without Delta, may not be detected analyzing delta frequencies, and may be present in large occlusive infarcts with poor outcome (Schneider and Jordan, 2005).

In other studies, qEEG brain symmetry parameters have been associated with functional outcome (van Putten and Tavy, 2004; de Vos et al., 2008; Sheorajpanday et al., 2009, 2010, 2011b). In our study, however, qEEG symmetry indices were not significant on multivariate analysis. We used an average montage before performing spectral analysis, which may reduce asymmetries between oscillatory brain activities.

We have also shown that the discriminative capacity of EEG characteristics obtained from visual EEG analysis is similar to qEEG indices. This is an important finding, as visual EEG analysis is cumbersome and dependent on trained neurophysiologists. In contrast, qEEG indices can be readily and easily available in a stroke unit and can be interpreted by all health personnel. 
One important finding in our study is the weaker effect of CT imaging lesion size (ASPECTS), obtained from the first CT scan after stroke, when compared to DTABR and alpha RP in outcome prediction. To date, no previous study has compared ASPECTS with qEEG parameters in outcome prediction. Although neuroimaging with CT adds invaluable diagnostic information for stroke patients, this technique has several limitations regarding lesion volume determination especially in the acute/hyperacute phase (Sillanpaa et al., 2011). During this period, qEEG data may be more reliable and easy to monitor, especially in intensive care settings.

Several limitations of this work are common to other qEEG studies. Effective identification and exclusion of EEG artifacts may be a challenge, such as muscle artifacts interfering with faster activities, or eye movements with delta activity. In our study, besides using an automatic method for artifact removal, an additional visual rejection was done. This may render the results less applicable to qEEG measures in intensive care units, when depending solely upon automatic artifact removal. These results were also obtained from 62-channels EEG that are not routine for EEG monitoring. Further studies are necessary to validate these data.

In conclusion, in a large, well defined cohort of acute anterior ischemic stroke patients, we found that the alpha RP or DTABR are qEEG variables that contribute significantly for post-stroke outcome prediction, at discharge and 12 months after stroke, when controlled for demographic, clinical and imaging variables.

\section{Conflict of interest statement}

This work was supported by the 2012 Research Grant in Cerebrovascular Diseases (scientific promoter: Sociedade Portuguesa do AVC - Sponsor: Tecnifar). Dr Ferro reports personal fees from Boehringer Ingelheim outside the submitted work. None of the other authors have potential conflicts of interest to be disclosed.

\section{Acknowledgements}

We are also obliged to EEG technicians Joana Pires, Lígia Ferreira and Rosa Santos. We are also grateful to all nurses and medical residents working in the stroke unit between 2011 and 2013 for their support to this project.

\section{Appendix A. Supplementary material}

Supplementary data associated with this article can be found, in the online version, at https://doi.org/10.1016/j.clinph.2018.05.021.

\section{References}

Adams HPJ, Davis PH, Leira EC, Chang KC, Bendixen BH, Clarke WR, et al. Baseline NIH stroke scale score strongly predicts outcome after stroke: a report of the Trial of Org 10172 in Acute Stroke Treatment (TOAST). Neurology 1999:53:126-31.

Assenza G, Zappasodi F, Pasqualetti P, Vernieri F, Tecchio F. A contralesional EEG power increase mediated by interhemispheric disconnection provides negative prognosis in acute stroke. Restor Neurol Neurosci 2013;31:177-88.

Banks JL, Marotta CA. Outcomes validity and reliability of the modified rankin scale: implications for stroke clinical trials - a literature review and synthesis. Stroke 2007;38:1091-6.

Barber P, Demchuk A, Zhang J, Buchan A. Validity and reliability of a quantitative computed tomography score in predicting outcome of hyperacute stroke before thrombolytic therapy. ASPECTS Study Group. Alberta Stroke Programme Early CT Score. Lancet 2000;355:1670-4.

Beniczky S, Hirsch LJ, Kaplan PW, Pressler R, Bauer G, Aurlien H, et al. Unified EEG terminology and criteria for nonconvulsive status epilepticus. Epilepsia 2013;54 (Suppl. 6):28-9.

Bentes C, Martins H, Peralta AR, Casimiro C, Morgado C, Franco AC, et al. Post-stroke seizures are clinically underestimated Available from:. J Neurol 2017a;264:1978-85. http://link.springer.com/10.1007/s00415-017-8586-9.
Bentes C, Martins H, Peralta AR, Morgado C, Casimiro C, Franco AC, et al. Epileptic manifestations in stroke patients treated with intravenous alteplase Available from:. Eur J Neurol 2017b;24:755-61. http://doi.wiley.com/10.1111/ene. 13292.

Bentes C, Peralta AR, Martins H, Casimiro C, Morgado C, Franco AC, et al. Seizures, electroencephalographic abnormalities, and outcome of ischemic stroke patients Available from:. Epilepsia Open 2017c;2:441-52. http://doi. wiley.com/10.1002/epi4.12075.

Cillessen JP, van Huffelen AC, Kappelle LJ, Algra A, van Gijn J. Electroencephalography improves the prediction of functional outcome in the acute stage of cerebral ischemia Available from:. Stroke 1994;25:1968-72. http://www.ncbi.nlm.nih.gov/pubmed/8091439.

Cuspineda E, Machado C, Aubert E, Galan L, Llopis F, Avila Y. Predicting outcome in acute stroke: a comparison between QEEG and the Canadian Neurological Scale Available from:. Clin Electroencephalogr 2003;34:1-4. http://www.ncbi.nlm. nih.gov/entrez/query.fcgi? cmd=Retrieve\&db=PubMed\&dopt=Citation\&list uids $=12515444$.

Cuspineda E, Machado C, Galán L, Aubert E, Alvarez MA, Llopis F, et al. QEEG prognostic value in acute stroke. Clin EEG Neurosci 2007:38:155-60.

de Vos CC, Van Maarseveen SM, Brouwers PJ, van Putten MJ. Continuous EEC monitoring during thrombolysis in acute hemispheric stroke patients using the brain symmetry index. J Clin Neurophysiol 2008;25:77-82.

Diedler J, Sykora M, Bast T, Poli S, Veltkamp R, Mellado P, et al. Quantitative EEC correlates of low cerebral perfusion in severe Stroke. Neurocrit Care 2009;11:210-6.

Diedler J, Sykora M, Jüttler E, Veltkamp R, Steiner T, Rupp A. EEG power spectrum to predict prognosis after hemicraniectomy for space-occupying middle cerebral artery infarction. Cerebrovasc Dis 2010;29:162-9.

Feigin VL, Norrving B, Mensah GA. Global burden of stroke. Circ Res 2017;120.

Finnigan S, van Putten MJAM. EEG in ischaemic stroke: quantitative EEG can uniquely inform (sub-)acute prognoses and clinical management. Clin Neurophysiol 2013;124:10-9. Available from: http://dx.doi.org/10.1016/ j.clinph.2012.07.003.

Finnigan S, Wong A, Read S. Defining abnormal slow EEG activity in acute ischaemic stroke: delta/alpha ratio as an optimal QEEG index Available from:. Clin Neurophysiol 2015;127:1452-9. http://linkinghub.elsevier.com/retrieve/pii/ S1388245715007233.

Finnigan SP, Rose SE, Chalk JB. Rapid EEG changes indicate reperfusion after tissue plasminogen activator injection in acute ischaemic stroke. Clin Neurophysiol 2006;117:2338-9.

Finnigan SP, Rose SE, Walsh M, Griffin M, Janke AL, McMahon KL, et al. Correlation of quantitative EEG in acute ischemic stroke with 30-day NIHSS score: comparison with diffusion and perfusion MRI Available from:. Stroke 2004;35:899-903. http://www.ncbi.nlm.nih.gov/pubmed/15001786.

Finnigan SP, Walsh M, Rose SE, Chalk JB. Quantitative EEG indices of sub-acute ischaemic stroke correlate with clinical outcomes. Clin Neurophysiol 2007:118:2525-32.

Frankel M, Morgenstern L, Kwiatkowski T, Lu M, Tilley B, Broderick J, et al. Predicting prognosis after stroke: a placebo group analysis from the National Institute of Neurological Disorders and Stroke rt-PA stroke trial. Neurology 2000;55:952-9.

Goldstein L, Bertels C, Davis J. Interrater reliability of the NIH stroke scale. Arch Neurol 1989;46:660-2.

Hankey GJ. Long-term outcome after ischaemic stroke/transient ischaemic attack Available from:. Cerebrovasc Dis 2003;16(Suppl 1):14-9. https://www. karger.com/Article/FullText/69936.

Hankey GJ, Spiesser J, Hakimi Z, Bego G, Carita P, Gabriel S. Rate, degree, and predictors of recovery from disability following ischemic stroke. Neurology 2007;68:1583-7.

Hirsch LJ, LaRoche SM, Gaspard N, Gerard E, Svoronos A, Herman ST, et al. American clinical neurophysiology society's standardized critical care EEG terminology: 2012 version. J Clin Neurophysiol 2013;30:1-27.

Kaplan PW, Rossetti AO. EEG patterns and imaging correlations in encephalopathy: encephalopathy part II. J Clin Neurophysiol 2011;28:233-51.

Knoflach M, Matosevic B, Rucker M, Furtner M, Mair A, Wille C, et al. Functional recovery after ischemic stroke - a matter of age. Neurology 2012;78:279.

Konig IR, Ziegler A, Bluhmki E, Hacke W, Bath PMW, Sacco RL, et al. Predicting longterm outcome after acute ischemic stroke: a simple index works in patients from controlled clinical trials. Stroke 2008;39:1821-6.

Murri L, Gori S, Massetani R, Bonanni E, Marcella F, Milani S. Evaluation of acute ischemic stroke using quantitative EEG: a comparison with conventional EEG and CT scan Available from:. Neurophysiol Clin 1998;28:249-57. http://www. ncbi.nlm.nih.gov/pubmed/9686400\%5Cnhttp://ac.els-cdn.com/ S0987705398801159/1-s2.0-S0987705398801159-main.pdf.

Nagata K, Tagawa K, Hiroi S, Shishido F, Uemura K. Electroencephalographic correlates of blood flow and oxygen metabolism provided by positron emission tomography in patients with cerebral infarction Available from: Electroencephalogr Clin Neurophysiol 1989;72:16-30. http://www.ncbi.nlm. nih.gov/pubmed/2464472.

Noachtar S, Binnie C, Ebersole J, Mauguière F, Sakamoto A, Westmoreland B. A glossary of terms most commonly used by clinical electroencephalographers and proposal for the report form for the EEG findings Available from:. Int Feder Clin Neurophysiol Electroencephalogr Clin Neurophysiol Suppl 1999;52:21-41. http://www.ncbi.nlm.nih.gov/pubmed/10590974. 
Nuwer MR, Jordan SE, Ahn SS. Evaluation of stroke using EEG frequency analysis and topographic mapping Available from:. Neurology 1987;37:1153-9. http:// www.ncbi.nlm.nih.gov/pubmed/3601079.

Rathakrishnan R, Gotman J, Dubeau F, Angle M. Using continuous electroencephalography in the management of delayed cerebral ischemia following subarachnoid hemorrhage. Neurocrit Care 2011;14:152-61.

Rossini PM, Altamura C, Ferretti A, Vernieri F, Zappasodi F, Caulo M, et al. Does cerebrovascular disease affect the coupling between neuronal activity and local haemodynamics? Brain 2004;127:99-110.

Sainio K, Stenberg D, Keskimaki I, Muuronen A, Kaste M. Visual and spectral EEC analysis in the evaluation of the outcome in patients with ischemic brain infarction. Electroencephalogr Clin Neurophysiol 1983;56:117-24.

Schleiger E, Sheikh N, Rowland T, Wong A, Read S, Finnigan S. Frontal EEG delta/ alpha ratio and screening for post-stroke cognitive deficits: the power of four electrodes. Int J Psychophysiol 2014;94:19-24. Available from: http://dx.doi. org/10.1016/j.ijpsycho.2014.06.012.

Schneider AL, Jordan KG. Regional attenuation without delta (RAWOD): a distinctive EEG pattern that can aid in the diagnosis and management of severe acute ischemic stroke Available from:. Am J Electroneurodiagnostic Technol 2005;45:102-17. http://www.ncbi.nlm.nih.gov/pubmed/15989073.

Schuijt TJ, Van Der Poll T, Wiersinga WJ. In: Annual update in intensive care and emergency medicine; 2012. p. 29-37. Available from: http://link.springer.com/ 10.1007/978-3-642-25716-2.

Sharbrough FW, Messick Jr JM, Sundt Jr TM. Correlation of continuous electroencephalograms with cerebral blood flow measurements during carotid endarterectomy Available from:. Stroke 1973;4:674-83. http://stroke. ahajournals.org/cgi/doi/10.1161/01.STR.4.4.674.

Sheorajpanday RVA, Nagels G, Weeren AJTM, De Deyn P. Quantitative EEG in ischemic stroke: correlation with infarct volume and functional status in posterior circulation and lacunar syndromes. Clin Neurophysiol 2011a;122:884-90. Available from: http://dx.doi.org/10.1016/ j.clinph.2010.08.020.

Sheorajpanday RVA, Nagels G, Weeren AJTM, van Putten MJAM, De Deyn PP. Reproducibility and clinical relevance of quantitative EEG parameters in cerebral ischemia: a basic approach. Clin Neurophysiol 2009;120:845-55.

Sheorajpanday RVA, Nagels G, Weeren AJTM, van Putten MJAM, De Deyn PP. Quantitative EEG in ischemic stroke: correlation with functional status after 6months. Clin Neurophysiol 2011b;122:874-83.

Sheorajpanday RVA, Nagels G, Weeren AJTM, De Surgeloose D, De Deyn PP. Additional value of quantitative EEG in acute anterior circulation syndrome of presumed ischemic origin. Clin Neurophysiol 2010;121:1719-25.

Sillanpaa N, Saarinen JT, Rusanen H, Hakomaki J, Lahteela A, Numminen $\mathrm{H}$, et al. CT perfusion ASPECTS in the evaluation of acute ischemic stroke: thrombolytic therapy perspective Available from:. Cerebrovasc Dis Extra 2011;1:6-16. http://www.karger.com/doi/10.1159/000324324.

Stinear C. Prediction of recovery of motor function after stroke. Lancet Neurol 2010;9:1228-32.

Szelies B, Mielke R, Kessler J, Heiss WD. Prognostic relevance of quantitative topographical EEG in patients with poststroke aphasia. Brain Lang 2002:82:87-94.

Tecchio F, Pasqualetti P, Zappasodi F, Tombini M, Lupoi D, Vernieri F, et al. Outcome prediction in acute monohemispheric stroke via magnetoencephalography. J Neurol 2007;254:296-305.

van Putten MJAM, Tavy DLJ. Continuous quantitative EEG monitoring in hemispheric stroke patients using the brain symmetry index Available from: Stroke 2004;35:2489-92. http://stroke.ahajournals.org/cgi/doi/10.1161/01. STR.0000144649.49861.1d.

Vogt G, Laage R, Shuaib A, Schneider A. Initial lesion volume is an independent predictor of clinical stroke outcome at day 90: An analysis of the Virtual International Stroke Trials Archive (VISTA) database. Stroke 2012;43:1266-72. 